\title{
Characterization of BSO crystals. A preliminary study
}

\author{
J. MARTÍNEZ, M. GONZÁLEZ-MAÑAS, M.A. CABALLERO, E. DIÉGUEZ* and \\ B. CAPELLE ${ }^{* *}$
}

Dpto. Estructura y Propiedades de los Materiales, Facultad de Ciencias (UCA), Apdo. 40, 11510 Pto. Real (Cádiz), Spain

* Dpto. Física Aplicada, Facultad de Ciencias (UAM), 28049 Cantoblanco (Madrid), Spain

** Lab. Minéralogie-Cristallographie, UA 009 du CNRS, Universités P. et M. Curie et Paris VII, BP. 115, 75252 Paris cedex 05, France

\begin{abstract}
Czochralski grown bismuth silicon oxide (BSO) crystals have been investigated by mean of synchrotron X-ray topography in order to study the quality of the crystals obtained. High quality single crystals can be obtained under conditions rather deviated from the equilibrium. The first results correlating the defects observed with the type of the interface are reported.
\end{abstract}

\section{INTRODUCTION}

Bismuth silicon oxide are an electro-optical, piezo-electric and photo-conductive material. These properties found applications in a number of technologically important electronic devices, such as high-frequency filters and waveguides, and also specially in optical devices for holographic recording of informations. These technological applications can be usefully achieved by improving the quality of the crystals currently obtained.

$\mathrm{Bi}_{2} \mathrm{O}_{3}-\mathrm{SiO}_{2}$ system phase diagram shows a homogeneity region corresponding to a melt of composition ranging from 13.3 to $15.5 \%$ of $\mathrm{SiO} 2$. The BSO crystals obtained from this melt have a stoechiometry $\mathrm{Bi}_{\mathrm{x}} \mathrm{SiO}_{1.5 \mathrm{x}+2}(\mathrm{x}=11.71-12.05)$. This composition is congruent with the melt [1]. Their atomic structure is described by the cubic space group I 23 .

The obtainment of high quality BSO crystals, which theoretically must have a plane interface, is obviously determined by several parameters controlling the growth process, in particular: the growth direction, the axial and radial temperature gradients, the rotation speed and the pulling rate. The authors have previously studied the influence of those parameters in the formation of convex, concave or plane crystal-melt interfaces, [2], which are characterized by a different location of the appearing facets and a different impurity distribution associated to the BSO growth process and to the hydrodynamic flow in the melt [3].

The aim of this work was to study the influence of the growth parameter variations in reference to the quality of the crystal obtained and to correlate the defects observed with the kind of crystal-melt interface.

\section{EXPERIMENTAL DETAILS}

BSO crystal have been grown from oxide mixtures of molar ratio $6 \mathrm{Bi}_{2} \mathrm{O}_{3}: 1 \mathrm{SiO}_{2}$ with the Czochralski technique using a diameter Control System. In order to minimize the reactivity with the melt, platinum crucible were used. Two kinds of heating elements, radio frequency and CSi resistance heaters, were used in the equipments for Czochralski growth. They proportion different hot zones. 
Different growth runs were carried out changing the parameters already mentioned: a) the growth direction [001] or [110]; b) the axial temperature gradient between 6 and $90^{\circ} \mathrm{C} / \mathrm{cm} ; \mathrm{c}$ ) the rotation rate between 15 and $50 \mathrm{rpm}$; d) the pulling rate between 1.0 and $3.3 \mathrm{~mm} / \mathrm{h}$. These conditions have been established according to [4]. Some of the most outstanding experiments are shown in the table 1 .

Table 1. Experimental growth conditions. $\mathrm{V}_{\mathrm{t}}$ : pulling rate $(\mathrm{mm} / \mathrm{h}) ; \mathrm{V}_{\mathrm{r}}$ : rotation rate $(\mathrm{rpm})$; $\Delta T$ : axial temperature gradient $\left({ }^{\circ} \mathrm{C} / \mathrm{cm}\right)$; G.D.: growth direction; $\Phi$ : crystal diameter $\left.(\mathrm{mm}) ; \mathrm{a}\right)$ single crystal; b) poly-crystal.

\begin{tabular}{|l|l|l|l|l|l|l|}
\hline SAMPLE & $\mathrm{V}_{\mathrm{t}}$ & $\mathrm{V}_{\mathrm{r}}$ & $\Delta T$ & $\mathrm{G} . \mathrm{D}$. & $\Phi$ & Interface \\
\hline $1_{\mathrm{a}}$ & 2.8 & 30 & 90 & {$[001]$} & 18 & Convex \\
\hline $2_{\mathrm{b}}$ & 2.8 & 30 & 90 & {$[001]$} & 18 & Convex \\
\hline $3_{\mathrm{b}}$ & 1.7 & 15 & 10 & {$[001]$} & 16 & Plane \\
\hline $4_{\mathrm{b}}$ & 1.0 & 30 & 48 & {$[001]$} & 22 & Concave \\
\hline
\end{tabular}

Some of the grown BSO crystals have been processed to be characterized by X-ray topography. Due to the high values of the absorption coefficient $\mu$, with respect to the usual sources of $X$-ray, experiments must be performed using a synchrotron radiation source. White beam transmission X-ray topographs of different slices perpendicular to the growth direction have been obtained. The thickness of the slices, $t$, was of the order of $150 \mu \mathrm{m}$; they were etched in a mixture $1: 4$ of $\mathrm{ClH}$ in $\mathrm{CH} 3 \mathrm{COOH}$. Likewise, chemical analysis have been carried out by energy dispersive $\mathrm{X}$-ray spectrometry.

\section{RESULTS AND DISCUSSION.}

Synchrotron radiation Laue topographs have shown the following results: The occurrence of BSO single crystal is irrespective of a strict control of the growth conditions provided that they are maintained within the limits of a stable growth [2],[4], table 1. Even crystals grown under conditions closer to the equilibrium which macroscopically have characters and morphology of single crystal may show a polycrystalline structure, Fig. 1. Such growth conditions are obtained by using smaller temperature gradients, and, rotation speed and pulling rates having values such to establish a compromise between the free and the induced Figure 1: Topography of a poly-crystal ( 3 in convection leading to a plane interface.

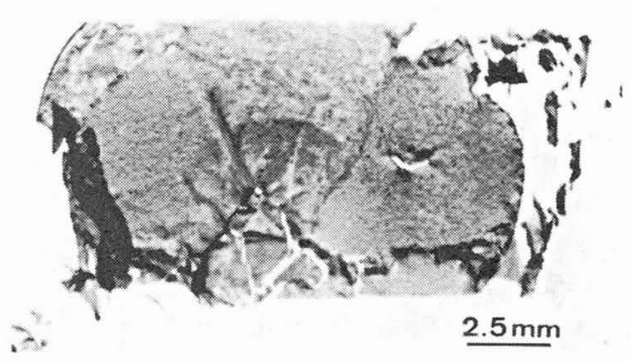

This fact prove that, beside the quality of the seed, all the physical and geometrical parameters having some influence in the neck and shoulder formation are critical in the attainment of BSO single crystal. Moreover high quality crystal can be obtained even under conditions of large temperature gradient. 

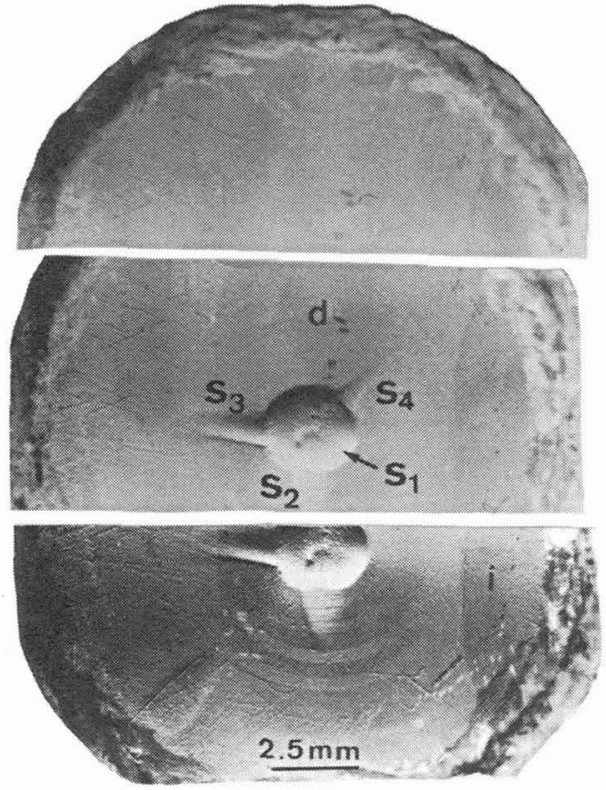

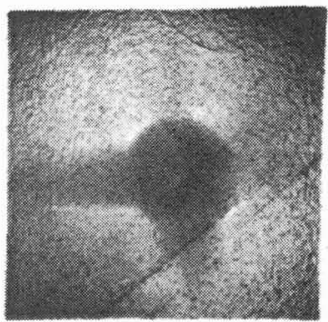

Figure 3: Optical micrograph of the core of crystal 1 .

Figure 2: Topography of a single crystal ( 1 in the table). 600 reflection, $\lambda=0.49 \mathrm{~A}, \mu \mathrm{t}=6.29$.

As Fig. 2 reveals, the predominant strains in the single crystal grown under high supercooling are associated to weak growth bands whose morphology is mainly circular, and to different growth facets. The facets distributed only in the central part of the crystal, corresponding to a convex interface, are of the type: $s_{1}(001), s_{2}(101), s_{3}(0 \overline{1} 1)$ and $s_{4}(\overline{111})[5]$.

The facets appear as a consequence of thermal instabilities at the crystal-melt interface which is not rigourously isothermal. Some inclusions, $i$, and very few dislocations, $d$, appear in this crystal excepting at the bordering zone $s$ where there is a high concentration of defects due to the hydrodynamics of the melt during the growth of these crystal.

On the other hand, topographs allow us to establish a clear correlation between the core of the crystal, optically visible by a darker colouration, Fig. 3, and the central facets.

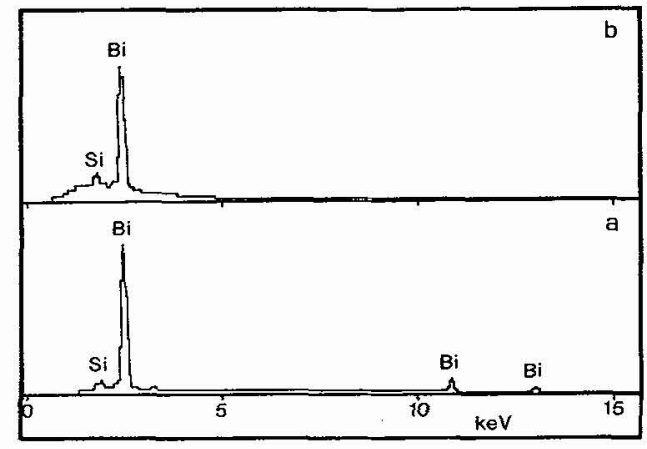

Figure 4: EDX spectres of crystal 1.a) core crystal and b) surrounding zones.

EDX analysis do not show any deviation in the chemical composition between the different growth zones. Nevertheless the spectres in the core of the crystal display the bismuth $L \alpha$ and $L \beta$ lines which are absent in the surrounding zones. This can be noticed in Fig. 4. According to [1], this effect seems to be related to the preferential incorporation of $\mathrm{Bi}^{+5}$ in the $\mathrm{BSO}$ crystal core. 
Our results also show that there is a good correlation between the density and distribution of the etch pits, the inhomogeneities of the interference colours and the diffraction contrasts in the polycrystalline samples leading to a rapid and easy way to check up the polycrystalline structure of the crystal obtained.

\section{ACKNOWLEDGMENTS}

This work has been supported by Project PB90-833 of the Spanish "Direccion General de Investigacion Cientifica y Técnica". Topographs were performed at "LURE" in Orsay, France, which are acknowledged for the allocation of time on the facilities.

\section{REFERENCES}

[1] Brice J.C., Hight M.J., Hill O.F. And Whiffin P.A.C., Philips Tech. Rev. 37 (1977) 250-262.

[2] Martinez-Lopez J., Caballero M.A., Santos M.T., Arizmendi L. And Dieguez E., J. Crystal Growth 128 (1993) 852-858.

[3] Whiffin P.A.C., Bruton T.M. And Brice J.C., J. Crystal Growth 32 (1976) 205-210.

[4] Brice J.C., Bruton T.M., Hill, O.F. And Whiffin P.A.C., J. Crystal Growth 24/25 (1974) 429-431.

[5] Kravchenko V.B., Kucha V.V. And Sovolev A.T., Sov. Phys. Crystallogr. 25 (1980) 638-641. 